\title{
Canales de calcio como blanco de interés farmacológico
}

\author{
Calcium channels as a pharmacological target
}

Lozano Jiménez Yenny Yolanda ${ }^{1}$, Sánchez Mora Ruth Mélida ${ }^{2}$

\section{Resumen}

Los canales de calcio son proteínas de membrana que constituyen la vía más importante para el ingreso del ion calcio $\left(\mathrm{Ca}^{2+}\right)$ a la célula. $\mathrm{Al}$ abrirse, permiten el ingreso selectivo del ion, iniciando una variedad de procesos como contracción muscular, secreción endocrina y liberación de neurotransmisores, entre otros. Estas proteínas se agrupan en tres categorías de acuerdo con sus propiedades estructurales y funcionales: (i) Canales de $\mathrm{Ca}^{2+}$ operados por interacción receptor-ligando (ROCC), (ii) Canales activados por parámetros físicos (Transient Receptor Potencial, TRP) y (iii) Canales de Calcio dependientes de voltaje (VDCCs), siendo estos últimos los más estudiados debido a su presencia en células excitables. Dada la importancia de $\mathrm{Ca}^{2+}$ en la fisiología celular, los canales de $\mathrm{Ca}^{2+}$ constituyen un punto de acción farmacológica importante para múltiples tratamientos y, por tanto, son objeto de estudio para el desarrollo de nuevos fármacos. El objetivo de esta revisión es explicar la importancia de los canales de $\mathrm{Ca}^{2+}$ desde una proyección farmacológica, a partir de la exploración documental de artículos publicados hasta la fecha teniendo en cuenta temas relacionados con la estructura de los canales $\mathrm{Ca}^{2+}$, sus propiedades biofísicas, localización celular, funcionamiento y su interacción farmacológica.

Palabras claves: Receptor, ligando, voltaje, despolarización, potencial, canal de calcio, bloqueadores de canales de calcio. 


\section{Abstract}

Calcium channels are membrane proteins that constitute the most important route for the entry of the calcium ion $\left(\mathrm{Ca}^{2+}\right)$ into the cell. When opened, they allow selective ion entrance, starting a variety of processes such as muscular contraction, endocrine secretion and neurotransmitters release, among others. These proteins are classified in three categories according to their structural and functional properties: (i) Receptor-operated calcium channels (ROCC), (ii) Channels activated by physical parameters (Transient Receptor Potential or TRP-channels) and (iii) Voltage-dependent calcium channels (VDCCs), the latter being the most studied due to its presence in excitable cells. Given the importance of $\mathrm{Ca}^{2+}$ in the cellular physiology, the calcium channels constitute targets for pharmacological action for multiple treatments, and therefore, they are object of study for the development of new medicaments. The objective of this review is to explain the importance of the channels of $\mathrm{Ca}^{2+}$ from a pharmacological projection, by exploring the articles published, bearing in mind topics related to the structure of the channels $\mathrm{Ca}^{2+}$, properties of their biophysics, cellular location, functioning and their pharmacological interaction.

Keywords: Receiver, ligand, Voltage, depolarization, potential, ion channel, calcium channel, calcium channel blockers.

\section{Introducción}

Los canales de calcio son un grupo amplio de proteínas integrales de membrana que se caracterizan por tener un poro acuoso que atraviesa la totalidad de la bicapa lipídica. Estas proteínas proporcionan una vía para que los iones $\mathrm{Ca}^{2+}$ ingresen al interior celular y puedan activar rutas de señalización intracelular (1). Los canales se caracterizan por ser altamente selectivos (2-5), y por fluctuar entre un estado abierto, cerrado e inactivo (3). Se abren sólo en respuesta a un estímulo específico, que puede ser un cambio de voltaje a través de la membrana, la unión de un ligando específico o incluso estímulos físicos, como $\mathrm{pH}$ o variaciones en la temperatura (6-8). Un sistema de clasificación general de estos canales los agrupa en tres clases diferentes: canales de $\mathrm{Ca}^{2+}$ operados por receptor o ROCC (por sus siglas en inglés Receptor Operated Calcium Channel), canales activados por parámetros físicos o TRP (por sus siglas en inglés Transient Receptor Potencial) y canales de calcio dependientes de voltaje o VDCCs (por sus siglas en inglés Voltage-gated Calcium Channels ) (8-12) (ver Figura 1). 
Figura 1. Clasificación de los canales de calcio de acuerdo a su mecanismo de acción.

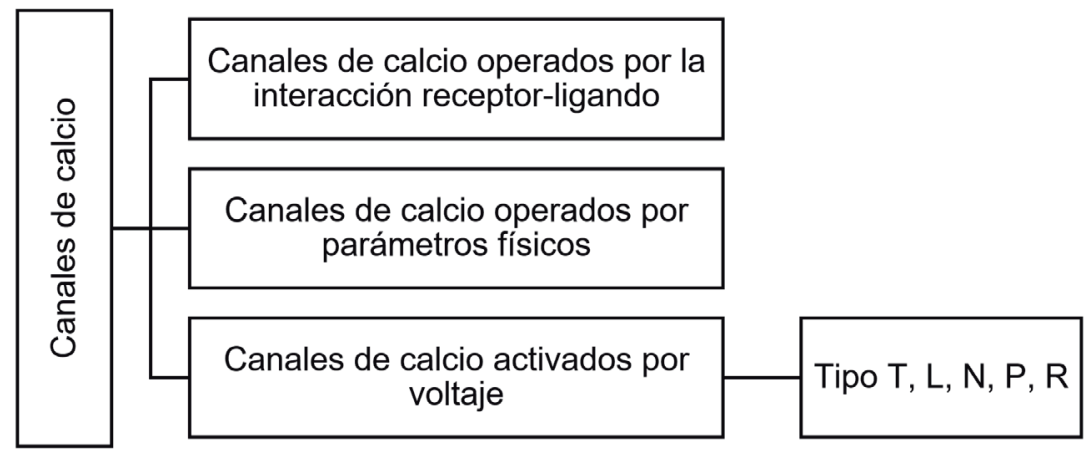

Fuente: Elaborado por Lozano y Sánchez.

La estructura de estos canales los hacen importantes blancos terapéuticos, por esta razón entender los diferentes componentes moleculares que participan en la regulación de su actividad y su relación con las vías de señalización celular permitirá proponer nuevos potenciales puntos de acción farmacológica.

\section{Canales de $\mathrm{Ca}^{2+}$ operados por receptor}

Los canales iónicos operados por la interacción receptor-ligando constituyen una familia de proteínas que permiten el paso de los iones después de que un ligando se ha unido al receptor (13). Los principales receptores operados por la interacción receptor-ligando son el receptor nicotínico, el receptor GABA A (ácido Y-aminobutírico), receptor glicina y receptor NMDA (N-metil-D-aspartato). De este conjunto el mejor ejemplo de un canal de $\mathrm{Ca}^{2+}$ operado por receptor es NMDA $(13,14)$. Este canal se encuentra constituido por 4 subunidades $(a, \beta, Y, \delta)$ que se ensamblan en la membrana celular como una estructura pentamérica (ver Figura 2), en la que una o varias subunidades pueden estar repetidas. Estructuralmente, el canal consiste de cuatro segmentos transmembrana (M1-M4) de los cuales el segmento M2 forma la pared del canal $(13,15)$. 
Figura 2. Característica estructural de los receptores operados por la interacción receptor ligando. Las subunidades se encuentran constituidas de 4 segmentos transmembrana (M1-M4).

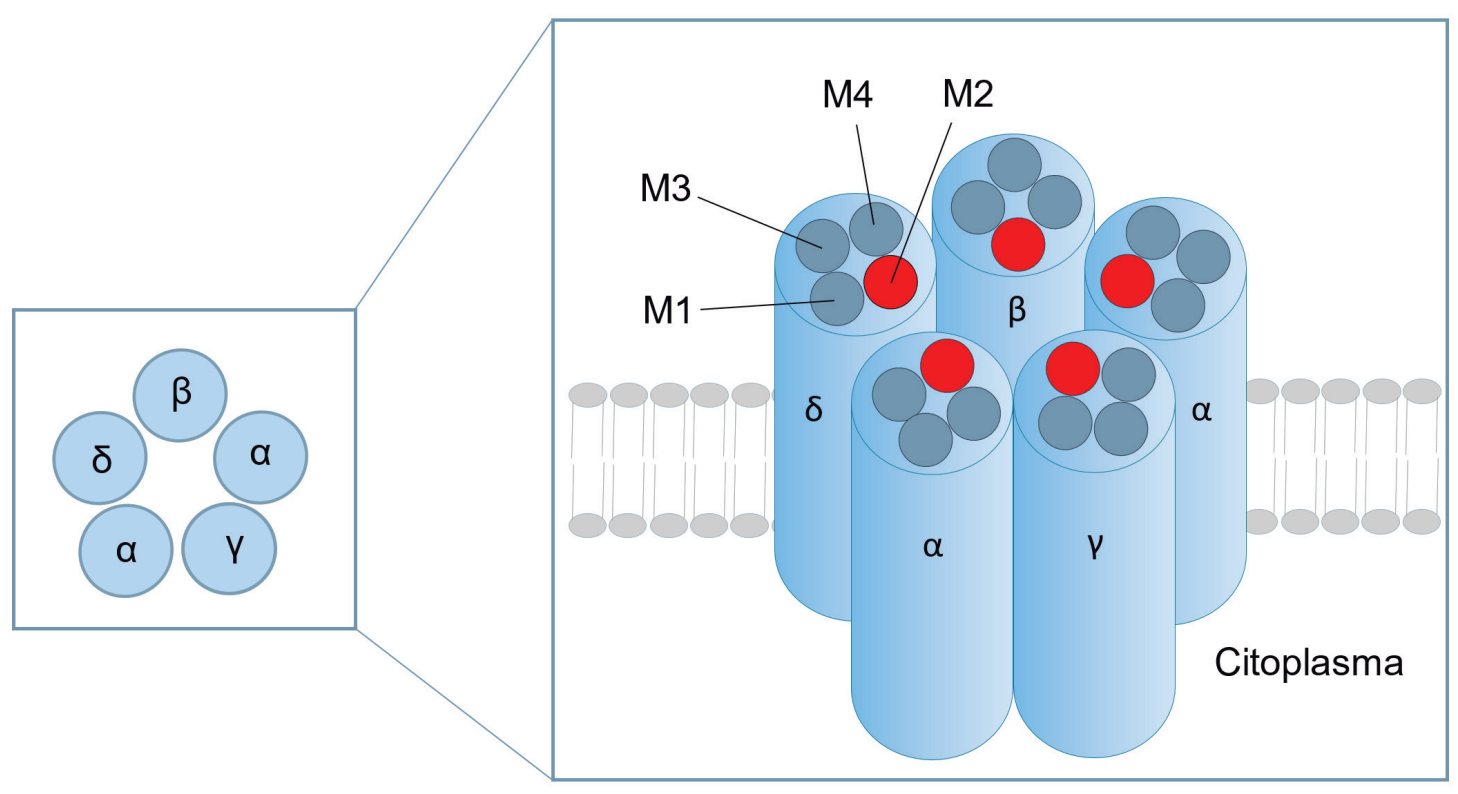

Fuente: Elaborado por Lozano y Sánchez.

El receptor NMDA es activado selectivamente por el N-metil-D-aspartato y por un co-agonista, el aminoácido glicina. Se caracteriza porque permite el flujo de $\mathrm{Na}^{+}$, $\mathrm{K}^{+} \mathrm{y} \mathrm{Ca}^{2+}(16,17)$. Este receptor comparte características funcionales con otros canales regulados por la interacción receptor-ligando y con canales dependientes de voltaje debido a que cuando el potencial de membrana está próximo al valor de reposo, el canal se encuentra bloqueado por el ion $\mathrm{Mg}^{2+}$ (18). El bloqueo es eliminado transitoriamente cuando la membrana se despolariza $(19,20)$.

Otro receptor con selectividad al ion calcio es el receptor nicotínico. La activación del receptor provoca la apertura del canal y el aumento de la permeabilidad iónica para cationes monovalentes $\mathrm{Na}^{+}, \mathrm{K}^{+}$y en menor proporción cationes divalentes como $\mathrm{Ca}^{2+} \mathrm{y}$ $\mathrm{Mg}^{2+}$, inducido por la unión de dos moléculas de acetilcolina en los extremo de la subunidades a $(21,22)$.

Otros canales pertenecientes a esta categoría son los receptores de inositol 1, 4, 5 trifosfato (IP3) y el receptor rianodina (RYR), ambos localizados en la membrana del retículo endoplásmico. Su activación se inicia con una señal extracelular que activa a los receptores acoplados a proteína $G$, lo que lleva a la activación de la enzima fosfolipasa C (PLC) para generar 1,2 diacilglicerol (DAG) e inositol 1,4,5 trifosfato (IP3). Este último se une a los receptores de IP3 produciendo la apertura del canal y la salida de $\mathrm{Ca}^{2+}$ desde el retículo al citosol celular (ver Figura 3) (23-25). 
Figura 3. Activación de los canales de $\mathrm{Ca}^{2+}$ del tipo operados por ligando. En este ejemplo se muestra la activación de los canales del tipo receptor IP3.

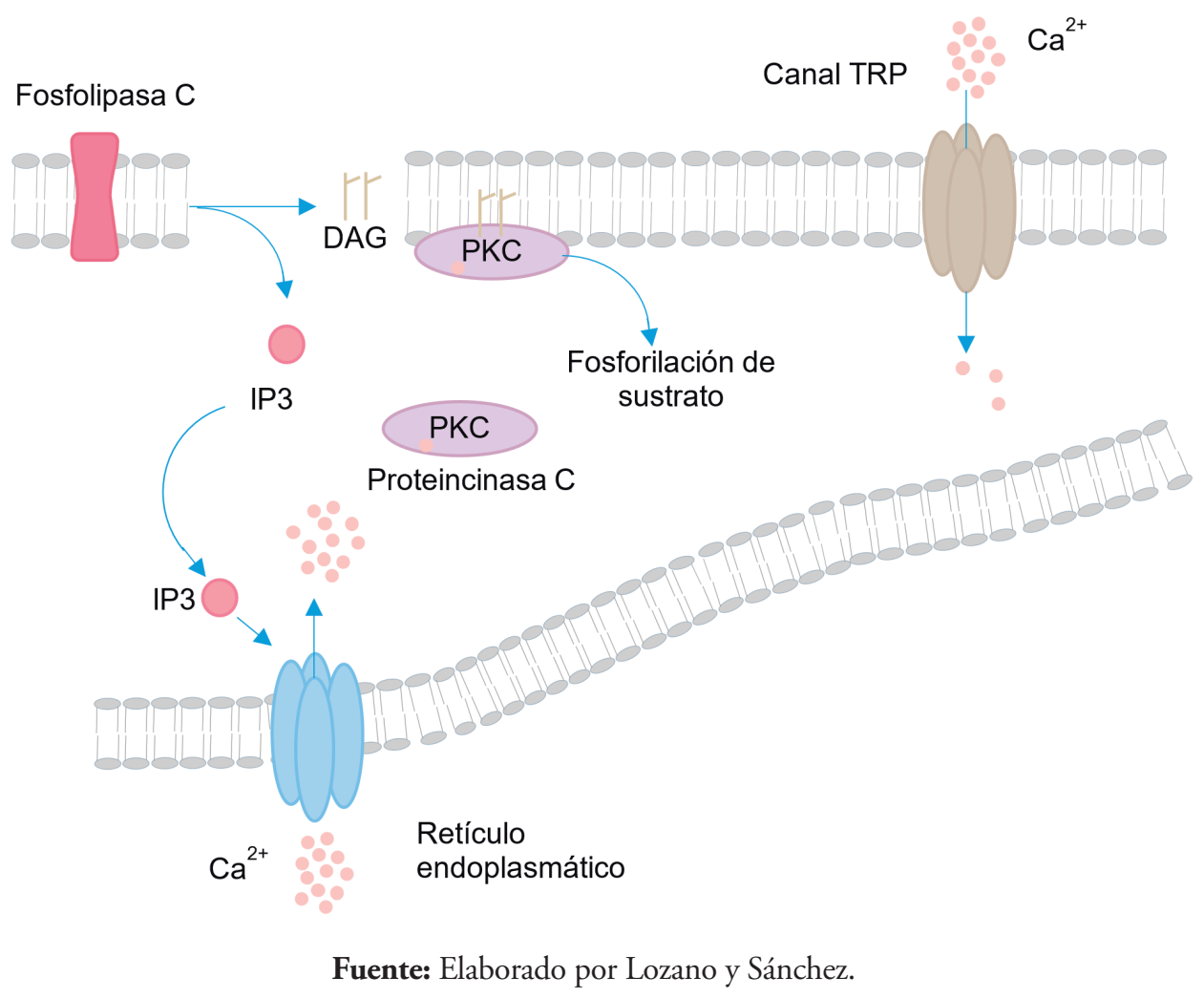

El vaciamiento de los depósitos intracelulares de calcio genera la apertura de los canales TRPs (Transient Receptor Potencial), lo que restablece el llenado de los depósitos de $\mathrm{Ca}^{2+}$ intracelular (ver Figura 3) (25).

\section{Canales TRPs}

Los miembros de la superfamilia de canales TRPs se caracterizan porque permiten el ingreso de $\mathrm{Ca}^{2+}$ y $\mathrm{Na}^{+}$al interior celular; se subdividen en 7 subfamilias: TRPC ('Canonical'), TRPV ('Vanilloid'), TRPM ('Melastatin'), TRPP ('Polycystin'), TRPML('Mucolipin'), TRPA ('Ankyrin') y TRPN ('NOMP') (26). Todos presentan una estructura común constituida de 6 dominios transmembrana, que se ensamblan en tetrámeros para formar el poro selectivo a cationes. Son ampliamente conservados y se encuentran expresados en diferentes células encontrando ejemplos de estas proteínas en prácticamente todos los tejidos $(27,28)$. La mayoría de los canales TRP tienen la habilidad de responder a una gran variedad de estímulos de origen muy diverso, tanto físicos (cambios en la temperatura, distensión de la membrana) como químicos ( $\mathrm{pH}$, hormonas, concentraciones iónicas), estos canales se han visto implicados en procesos de proliferación y diferenciación celular (29-32). 


\section{Canales de calcio dependientes de voltaje}

Se trata de una familia de proteínas bastante amplia que tiene en común la selectividad para $\mathrm{Ca}^{2+}$ y un mecanismo de activación dependiente de la despolarización de la membrana (potenciales mayores a $-60 \mathrm{mV}$ ) (33).
Su actividad también se encuentra regulada por diversas proteínas que operan sobre la porción intracelular del canal.

Los VDCCs presentan estructura oligomérica constituida por 4 subunidades $(a 1, \beta$, $a 2-\delta, y)$ (ver Figura 4).

Figura 4. Diagrama estructural de los canales de $\mathrm{Ca}^{2+}$ tipo VDCCs.

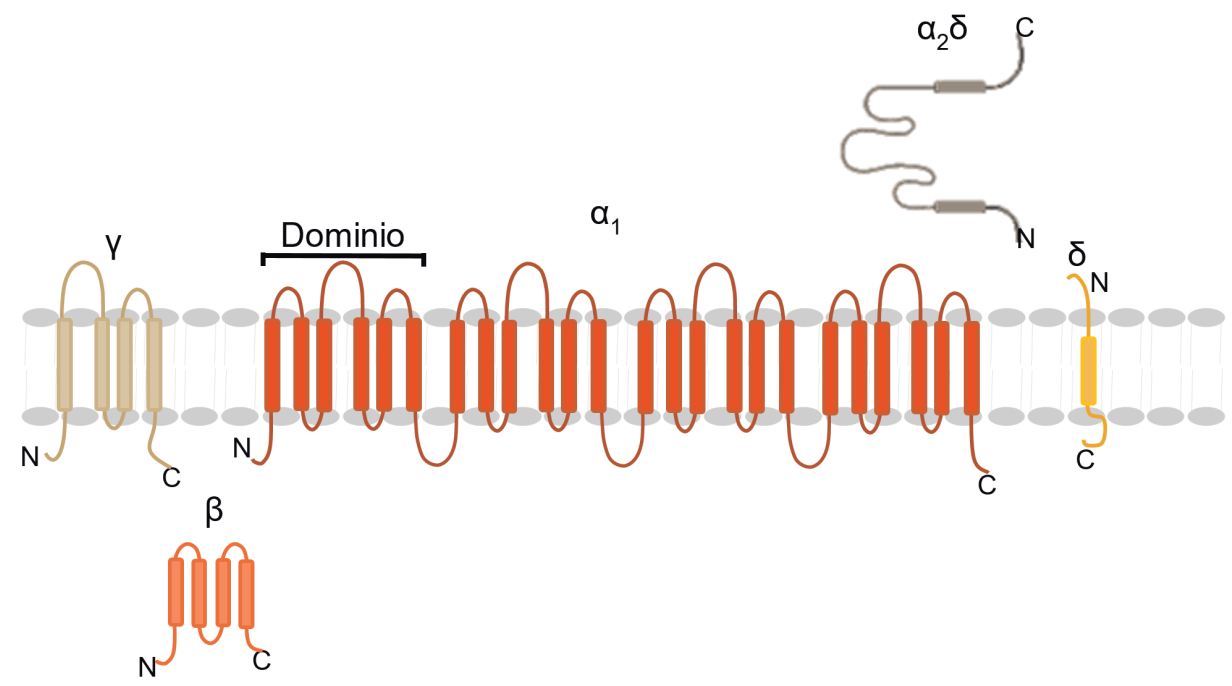

Fuente: Elaborado por Lozano y Sánchez.

La subunidad central a 1 es una glicoproteína con una masa molecular de 212 kilodalton $(\mathrm{kDa})$; consta de 4 dominios homólogos (I-IV), cada uno con 6 segmentos transmembrana (S1-S6) (34). Es la subunidad que forma el poro del canal para el paso de los iones $\mathrm{Ca}^{2+}(35)$ y su segmento $\mathrm{S} 4$ actúa como un sensor de voltaje para responder a un estímulo despolarizante. Presenta diez isoformas, cuya distribución es dependiente del tejido (ver Tabla 1), convirtiéndola en una unidad importante en los procesos de regulación de la concentración de calcio intracelular. 
Tabla 1. Clasificación de los canales de calcio dependientes de voltaje.

\begin{tabular}{|c|c|c|c|c|}
\hline Canal de calcio & Subunidad a1 & Tipo & Localización & Bloqueador específico \\
\hline $\begin{array}{l}\text { Cav1.1 } \\
\text { Cav1.2 } \\
\text { Cav1.3 } \\
\text { Cav1.4 }\end{array}$ & $\begin{array}{l}\text { a1s } \\
\text { a1C } \\
\text { a1D } \\
\text { a1F }\end{array}$ & $\mathrm{L}$ & $\begin{array}{l}\text { Músculo esquelético, } \\
\text { músculo cardiaco, células } \\
\text { endocrinas, neuronas, retina }\end{array}$ & DHPs, FAAs, BTZs \\
\hline $\begin{array}{l}\text { Cav2.1 } \\
\text { Cav2.2 } \\
\text { Cav2.3 }\end{array}$ & $\begin{array}{l}\mathrm{a} 1 \mathrm{~A} \\
\mathrm{a} 1 \mathrm{~B} \\
\mathrm{a} 1 \mathrm{E}\end{array}$ & $\begin{array}{c}\mathrm{P} / \mathrm{Q} \\
\mathrm{N} \\
\mathrm{R}\end{array}$ & Neuronas & $\begin{array}{c}\omega \text {-Agatoxina IVA } \\
\omega \text {-Conotoxina GVIA }\end{array}$ \\
\hline $\begin{array}{l}\text { Cav3.1 } \\
\text { Cav3.2 } \\
\text { Cav3.3 }\end{array}$ & $\begin{array}{l}\text { a1G } \\
\text { a1H } \\
\text { a1I }\end{array}$ & $\mathrm{T}$ & $\begin{array}{l}\text { Músculo esquelético, } \\
\text { músculo cardiaco, neuronas }\end{array}$ & Curtoxina \\
\hline
\end{tabular}

Fuente: Elaborado por Lozano y Sánchez.

La subunidad $\beta$, por su parte, es una proteína de naturaleza hidrofílica con una masa molecular de $54 \mathrm{kDa}$. En cuanto a su función, participa en el tráfico de la subunidad a 1 a la membrana plasmática y regula las propiedades cinéticas (activación e inactivación). Sin embargo, se desconocen los mecanismos por los cuales la subunidad $\beta$ es capaz de regular la actividad de la subunidad a1 (ver Figura 4) (36).

La subunidad $a 2 \delta$ es una glicoproteína constituida por la subunidad a2 de 143 $\mathrm{kDa}$ y $\delta$ de $27 \mathrm{kDa}$, unidas por puentes disulfuro. Se ha descrito que puede ser importante en la apertura del canal de $\mathrm{Ca}^{2+}$ (37) y además se sugiere que presenta una alta afinidad por el fármaco anticonvulsionante gabapentina (ver Figura 4) $(38,39)$.

La subunidad $Y$ es una glicoproteína de $30 \mathrm{kDa}$ que posee 4 segmentos transmembrana. Se sugiere que podría jugar un papel importante en el acoplamiento excitación-contracción (ver Figura 4) (37).
Los VDCCs se clasifican de acuerdo con sus propiedades biofísicas, según sea el potencial requerido para activarse (alto o bajo) (40). Los canales tipo L (Long Lasting Current), se inactivan lentamente y requieren un alto potencial para su activación; los de tipo T (Transient Current) se caracterizan porque requieren un bajo potencial para su activación y su inactivación es rápida. Los canales tipo $\mathrm{N}$ (Neither $\mathrm{T}$ Nor L) poseen unas características electrofisiológicas intermedias entre los canales tipo $\mathrm{T}$ y L (33).

Los VDCCs también se clasifican de acuerdo con sus propiedades farmacológicas, es decir, de acuerdo con la respuesta que presentan frente a ciertos fármacos. Así, los de tipo $L$ son sensibles a dihidropiridina (DHP), mientras que los del de tipo P/Q, $\mathrm{N}$ y $\mathrm{R}$ no responden a DHP, sino a otras moléculas (ver Tabla 1) (41).

Como ya se mencionó, los VDCCs se activan por un estímulo despolarizante. El sensor de voltaje ubicado en el segmento S4 
de la subunidad a1 detecta el cambio de potencial de la membrana, provocando un cambio conformacional que abre el canal y permite el ingreso de iones $\mathrm{Ca}^{2+}$ a la célula (25). Otro mecanismo de regulación de la activación de los VDCCs está dado indirectamente por los receptores $\beta 1, \beta 2$ adrenérgicos. El acoplamiento de éstos a la proteína heterotrimérica acoplada del tipo Gas, lleva al aumento de la concentración de AMP cíclico (AMPc); el que, a su vez, activa la proteíncinasa $\mathrm{C}$, con la consecuente fosforilación de los residuos serina y/o treonina de una o más subunidades del canal (42) (ver Figura 5).

Figura 5. Activación de VCDDs a partir de la activación de un receptor $\beta$-adrenérgico.

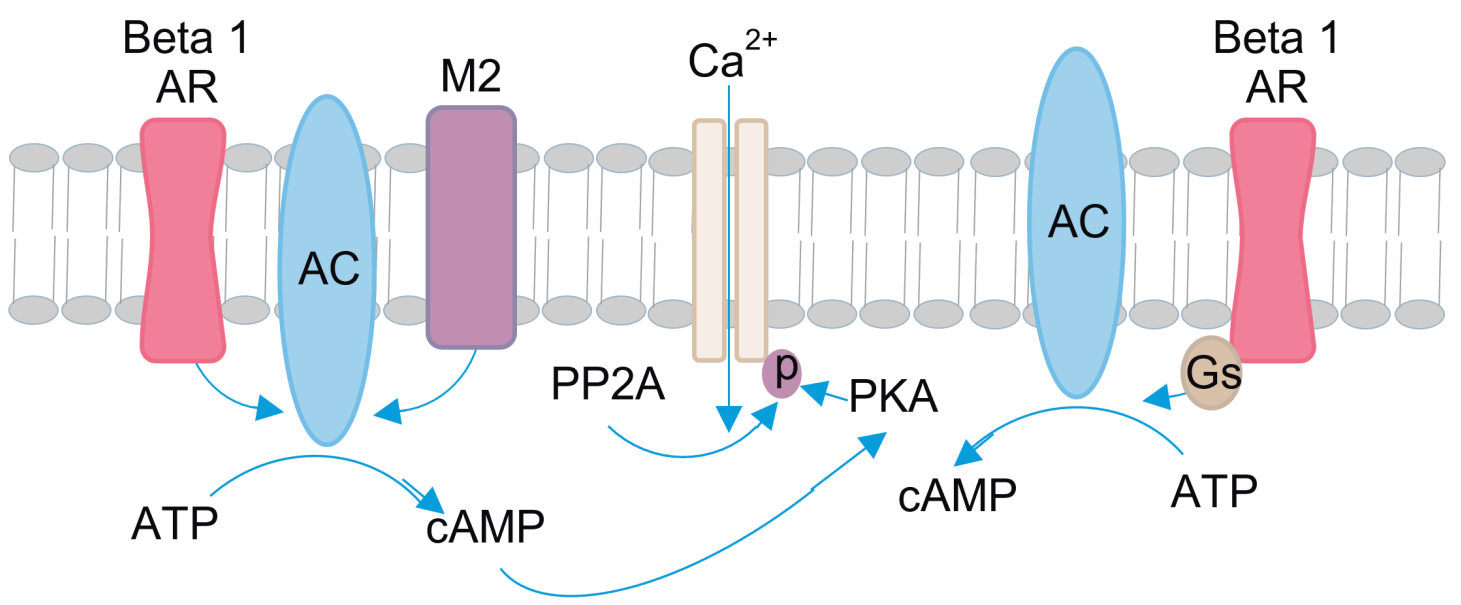

Fuente: Elaborado por Lozano y Sánchez.

\section{Calcio en un contexto fisiológico}

El calcio es uno de los principales mensajeros celulares. Está implicado en numerosas vías de señalización que regulan procesos tan importantes como secreción, contracción, proliferación y apoptosis celular (43). Sus implicaciones fisiológicas son, por lo tanto, diversas y de gran interés investigativo.

En condiciones fisiológicas, la concentración de $\mathrm{Ca}^{2+}$ dentro del citoplasma se mantiene en niveles muy bajos, alrededor de 100
nM. En contraste, la concentración de este ion en el espacio extracelular y en ciertos organelos citoplasmáticos internos, como el retículo endoplasmático o la mitocondria es 10.000-20.000 veces mayor (44). Este gradiente de $\mathrm{Ca}^{2+}$ se mantiene en parte por la acción de bombas de calcio que existen en la membrana plasmática y en la membrana del retículo endoplasmático, las cuales mueven $\mathrm{Ca}^{2+}$ por un mecanismo de transporte activo hacia el exterior de la célula o hacia el interior del reservorio intracelular, respectivamente, en contra del gradiente electroquímico (45). Un sistema adicional 
de transporte lo constituye el intercambiador $\mathrm{Na}^{+} / \mathrm{Ca}^{2+}$ que utiliza tres iones de $\mathrm{Na}^{+}$ para impulsar la salida de un ion $\mathrm{Ca}^{2+}(25)$.

Por acción de señales extracelulares como hormonas y neurotransmisores se genera un rápido aumento en la concentración de $\mathrm{Ca}^{2+}$ en el citosol celular $(46,47)$, que proviene de la apertura de canales de $\mathrm{Ca}^{2+}(46$, 48, 49). El incremento de $\mathrm{Ca}^{2+}$ intracelular modula la actividad de diversas proteínas como calmodulina, troponina $\mathrm{C}$, calpainas y otras proteínas de unión a $\mathrm{Ca}^{2+}$ (calbindina, calreticulina, calsecuestrina) (44), las cuales activan diferentes efectores desencadenando cambios en la actividad celular.

\section{Ca2+ en la contracción muscular}

$\mathrm{El}$ ion $\mathrm{Ca}^{2+}$ es un regulador fisiológico clave para la contracción muscular. En el músculo esquelético y cardiaco el proceso se ini- cia con la llegada de un impulso nervioso que lleva a la activación de los VDCCs. El consiguiente flujo de iones $\mathrm{Ca}^{2+}$ hacia el citoplasma incrementa la concentración de $\mathrm{Ca}^{2+}$ citosólico lo suficiente para influir en la interacción de las proteínas contráctiles actina, miosina, tropomiosina (TM) y troponina (Tn) (50) (ver Figura 6A). El movimiento de la miosina a lo largo del filamento de actina se encuentra regulado por el complejo TN -TM, siendo TN la unidad fijadora $\mathrm{Ca}^{2+}$ que regula la posición de TM (ver Figura 6b). El aumento de $\mathrm{Ca}^{2+}$ intracelular permite la fijación de iones a TN generando un cambio conformacional que permite el movimiento de TM; por lo tanto, se anula el efecto inhibidor del complejo TN-TM, permitiendo que la miosina se pueda fijar al filamento delgado de actina con la consecuente contracción muscular (ver Figura 6B) (51-53).

Figura 6. $\mathrm{Ca}^{2+}$ en la contracción muscular.

A. Contracción actina-miosina en músculo. B. Regulación de la contracción muscular.
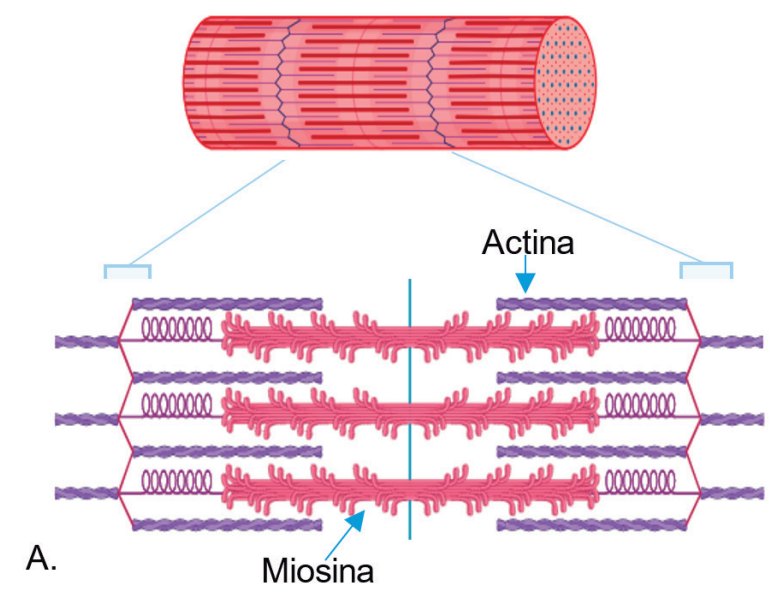

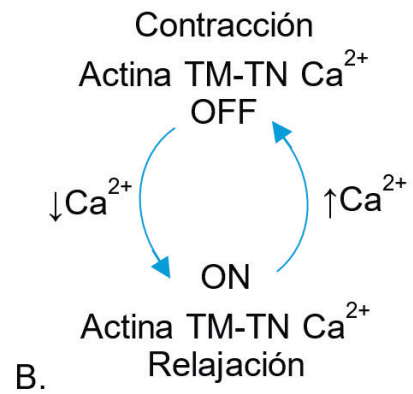

Fuente: Elaborado por Lozano y Sánchez. 
A nivel del músculo liso la contracción se origina por la presencia de diversos estímulos contráctiles que contribuyen al aumento en la concentración de calcio intracelular. Este $\mathrm{Ca}^{2+}$ citosólico se une a la proteína calmodulina formando un complejo calcio-calmodulina, $\left(\mathrm{Ca}^{2+}-\mathrm{CM}\right)$, que activa la quinasa de cadena ligera de la miosina (MLCK) (ver Figura 7A), la que a su vez fosforila la cadena ligera de la miosina (LC) facilitando su interacción con la actina y la contracción muscular (ver Figura 7B). La relajación muscular se produce cuando disminuyen los niveles de $\mathrm{Ca}^{2+}$ intracelular, lo que reduce la actividad de la MLCK y hace que predomine la actividad de la fosfatasa de la cadena ligera de la miosina (MLCP) que defosforila e inactiva la LC (25).

Figura 7. Contracción músculo liso.

A. Fosforilación del músculo liso B. Regulación de la contracción muscular en músculo liso.

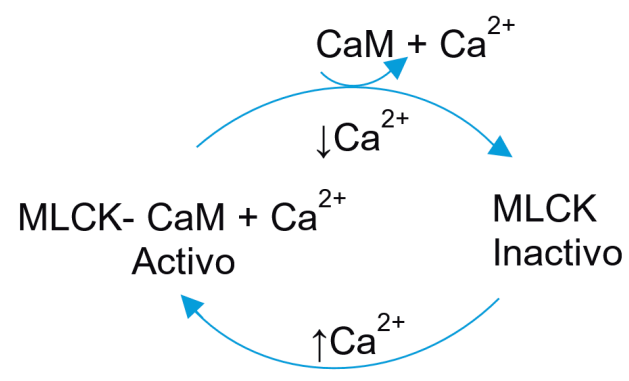

A.

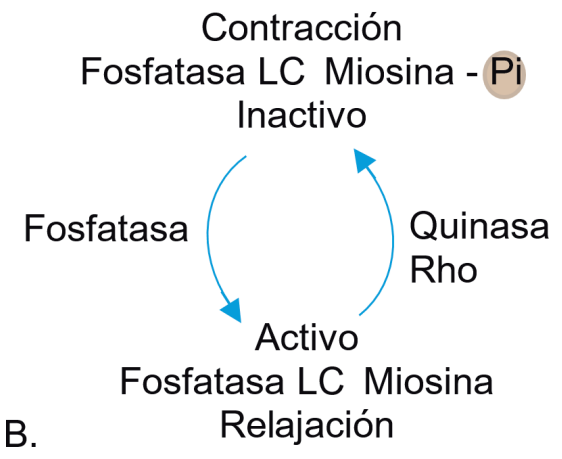

Fuente: Elaborado por Lozano y Sánchez.

\section{Calcio en la neurotransmisión}

La liberación de neurotransmisores por el proceso de exocitosis es un proceso dependiente de $\mathrm{Ca}^{2+}$ en el cual intervienen diversas proteínas. El proceso se inicia cuando llega un potencial de acción a la terminal presináptica, se activan los canales de $\mathrm{Na}^{+}$regulados por voltaje, ingresando $\mathrm{Na}^{+}$a favor de un gradiente de concentración. El flujo de cargas positivas despolariza la membrana plasmática lo que conduce a la apertura de los VDCCs y el respectivo ingreso del ion $\mathrm{Ca}^{2+}$ a la neurona (54). A nivel citoplasmático se activa la calmodulina por la unión de $\mathrm{Ca}^{2+}$, formándose un complejo $\mathrm{Ca}^{2+}$-calmodulina que activa una cascada de señalización conducente a la liberación de neurotransmisores por la fusión de las vesículas cargadas con neurotransmisores con la membrana plasmática, de acuerdo al modelo conocido como la hipótesis SNARE (55). Se ha propuesto que la sinaptotagmina, proteína presente en el complejo SNARE (ver Figura 8), evita la fusión de la vesícula con la membrana plasmática. Con el aumento de $\mathrm{Ca}^{2+}$ intracelular se presenta un cambio conformacional en esta proteína, siendo desplazada del complejo, permitiendo que otras proteínas se unan y se inicie el proceso de fusión $(56,57)$. 
Figura 8. Mecanismo de liberación de un neurotransmisor.

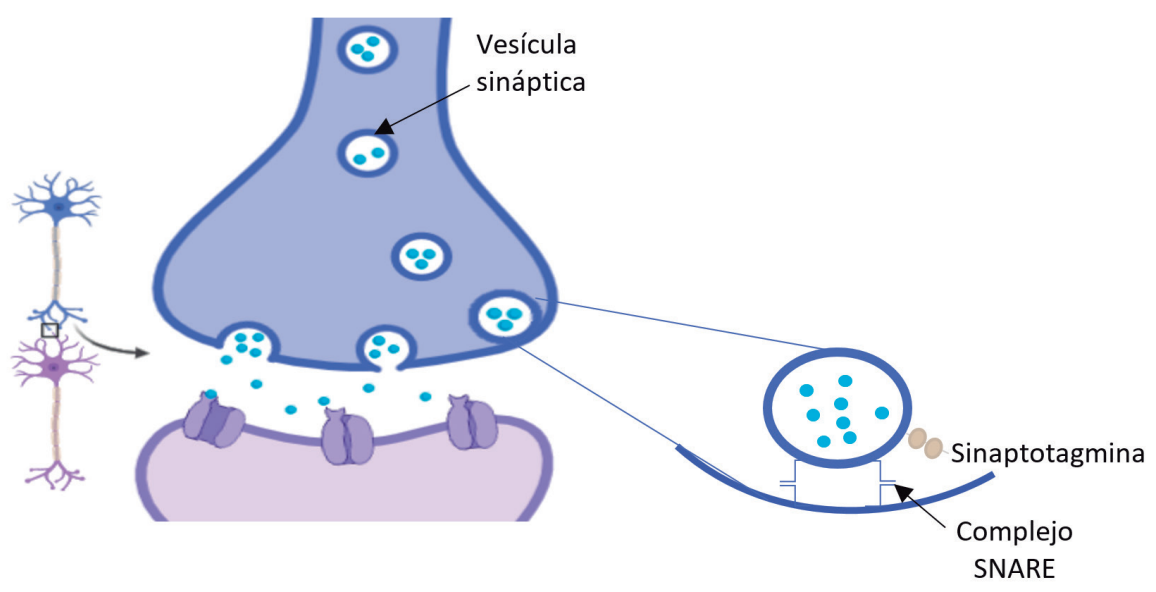

Fuente: Elaborado por Lozano y Sánchez.

\section{Calcio en la secreción de hormonas}

La secreción de hormonas es también un proceso dependiente de calcio. Análogo a lo recién descrito para la secreción de neurotransmisores, las vesículas conteniendo hormonas se unen con la membrana plasmática por el mismo mecanismo de fusión. La Figura 9 ejemplifica el proceso de secreción de insulina que ocurre en el páncreas. Des- pués del ingreso de glucosa a las células beta del páncreas, aumenta la concentración de ATP en el citoplasma. Este ATP se fija e inhibe los canales de $\mathrm{K}^{+}$sensibles a ATP, provocando una reducción de la salida de iones $\mathrm{K}^{+}$lo que genera una despolarización de la membrana plasmática y activación de los VDCCs. El ingreso de $\mathrm{Ca}^{2+}$ activa la fusión de las vesículas secretoras que contienen insulina (58-60) (ver Figura 9).

Figura 9. Secreción de insulina desde las células $\bigotimes$ pancreáticas en respuesta a un aumento de glucosa.

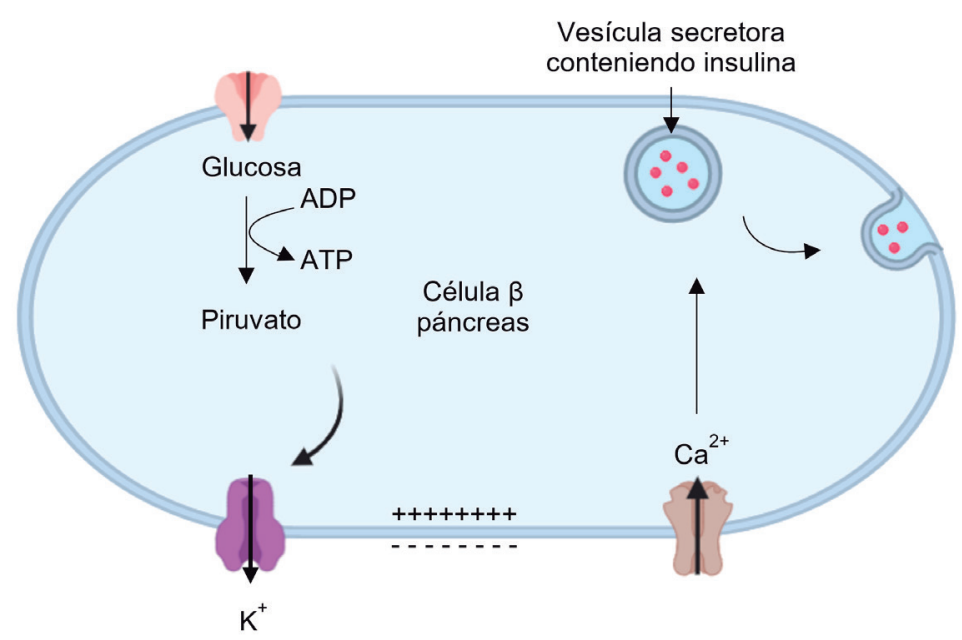

Fuente: Elaborado por Lozano y Sánchez. 


\section{Calcio en los potenciales de acción} cardiacos

El impulso cardíaco nace en el nodo sinoauricular (SA), se propaga a las aurículas, atraviesa el nodo auriculoventricular (AV) y mediante el sistema especializado de conducción His-Purkinje, invade ambos ventrículos que responden a la onda de propagación contrayéndose de forma sincrónica (54) (ver Figura 10A).

Figura 10. Calcio en los potenciales de acción cardiacos.

A. Esquema de las partes del corazón implicadas en el potencial de acción. B. Fases del potencial de acción.

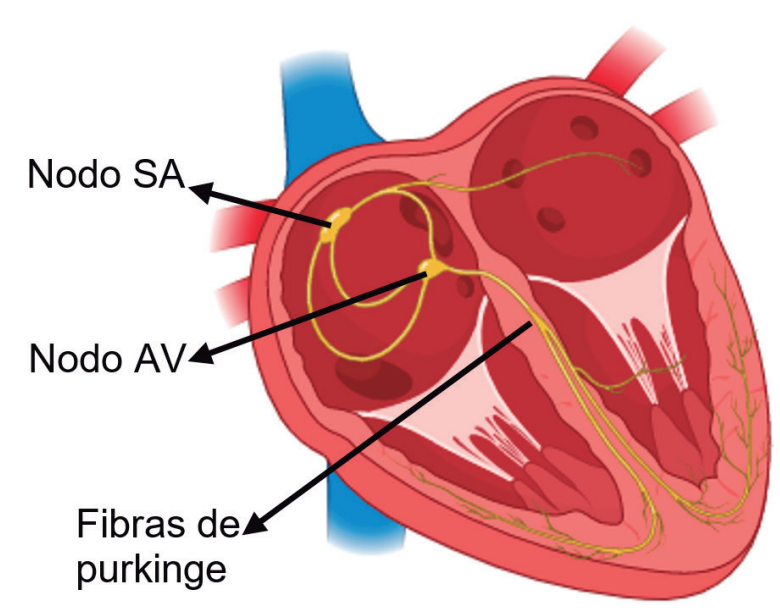

A.

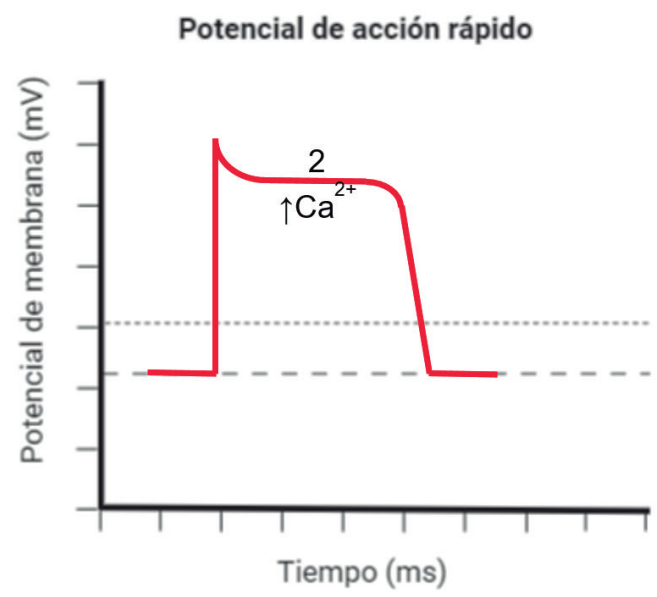

Diagrama de potencial de acción

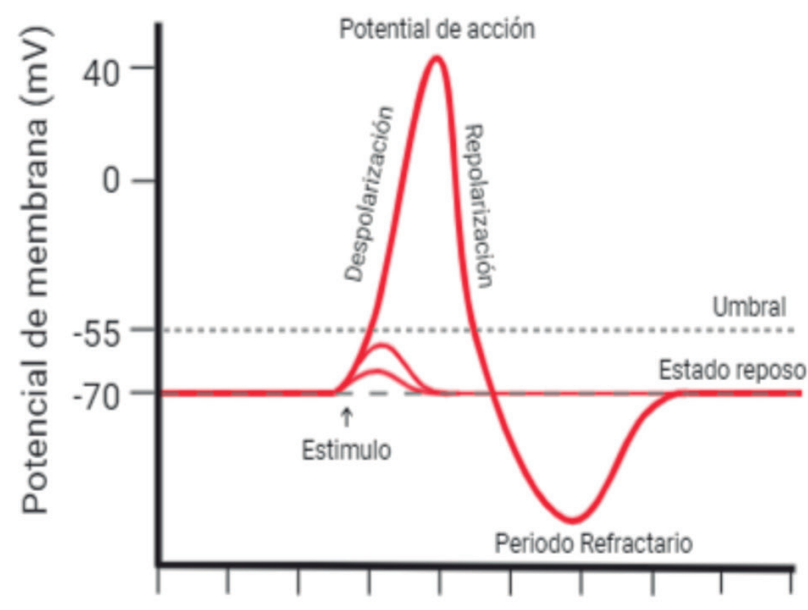

B.

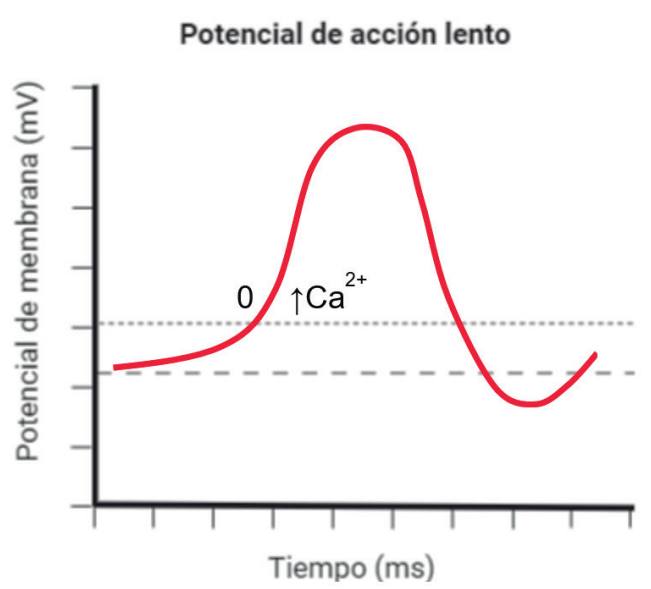

Fuente: Elaborado por Lozano y Sánchez. 
El ciclo cardiaco se encuentra controlado por variaciones en la concentración citosólica de $\mathrm{Ca}^{2+}$, que incrementa durante la sístole y disminuye durante la diástole. $\mathrm{El} \mathrm{Ca}^{2+}$ contribuye a la génesis del potencial de acción (ver Figura 10B). Cuando la célula cardiaca se despolariza produce una respuesta eléctrica denominada potencial de acción cardíaco; potenciales de acción rápidos o dependientes de $\mathrm{Na}^{+}$(en miocardio auricular, ventricular y sistema His-Purkinje) o lentos dependientes de $\mathrm{Ca}^{2+}$ (se presenta en el Nodo SA y Nodo AV) (ver figura Figura 10C). En ambos tipos de potencial la respuesta eléctrica depende del ingreso de $\mathrm{Ca}^{2+}$ a la célula.; En el primero de ellos, $\mathrm{Ca}^{2+}$ es importante para la fase 2 del potencial, y en el segundo caso, lo es para la fase 0 (ver figura Figura 10C).

\section{Otros papeles fisiológicos del $\mathrm{Ca}^{2+}$ intracelular}

El $\mathrm{Ca}^{2+}$ no sólo participa en los procesos fisiológicos anteriormente discutidos, que son efectos a corto plazo. También produce efectos a largo plazo que implican regulación de la expresión génica $(61,62)$. Se conoce que el aumento de $\mathrm{Ca}^{2+}$ intracelular lleva a la activación de factores de transcripción. Un ejemplo de ello es la proteína NFAT (Nuclear Factor of Activated T Cells) que pertenece a una familia de factores de transcripción que regulan la expresión de genes implicados en la respuesta inmune (63). Otro factor de transcripción regulado por $\mathrm{Ca}^{2+}$ es CREB (proteína de unión al elemento de respuesta a AMP cíclico) que regula la expresión de genes implicados en respuesta a diferentes estímulos (64).

Todo lo anterior resalta la importancia de $\mathrm{Ca}^{2+}$ en múltiples procesos fisiológicos importantes.

\section{Canales de Ca2+ y su interés farmacológico}

Los canales de calcio son el blanco de acción de diferentes fármacos empleados en la actualidad. El manejo farmacológico relacionado con estos canales está orientado mayoritariamente al sistema cardiovascular, especialmente para el tratamiento de arritmias, hipertensión, anginas y otros (ver Tabla 2). 
Tabla 2. Principales patologías asociadas a canales de calcio como blanco farmacológico.

\begin{tabular}{|c|c|c|}
\hline Patología & Acción del bloqueador & Tipo de canal involucrado \\
\hline Enfermedad arterial coronaria & $\begin{array}{c}\text { Se revierte el espasmo de los vasos coronarios; vasodilatación } \\
\text { coronaria y prevención de vasoconstricción coronaria; reducción del } \\
\text { gasto cardíaco; descenso en la resistencia vascular periférica }\end{array}$ & VDCCS tipo L \\
\hline Hipertensión & $\begin{array}{c}\text { Efecto vasodilatador. Se elige preferentemente nifedipina y DHP } \\
\text { más selectivos como vasodilatadores }\end{array}$ & VDCCS tipo L \\
\hline Vasculopatías periféricas & Acción vasodilatadora & VDCCS tipo L \\
\hline Arritmias & Inhibición del nodo auriculoventricular & VDCCS tipo L \\
\hline Insuficiencia vascular & Vasodilatador & VDCCS tipo L \\
\hline Neuropatía e insuficiencia renal & Efecto protector en la función renal & VDCCS tipo L \\
\hline Epilepsia & Impedir la propagación del impulso nervioso & VDCCS tipo T \\
\hline
\end{tabular}

Fuente: Elaborado por Lozano y Sánchez.

Todos los fármacos empleados actúan como bloqueadores de canales de calcio, y se clasifican en 1,4-dihidropiridinas (DHPs), benzotiazepinas y fenilalquilaminas (Tabla 3) (54).

Tabla 3. Principales fármacos usados en sistema cardiovascular.

\begin{tabular}{|c|c|c|}
\hline DIHIDROPIRIDINAS & BENZOTIAZEPINAS & FENILALQUILAMINAS \\
\hline Nifedipino & & \\
Amlodipino & Diltiazem & Verapamilo \\
Nimodipino & & \\
Nitrendipino & & \\
Nicardipino & & \\
Felodipino & & \\
\hline
\end{tabular}

Fuente: Elaborado por Lozano y Sánchez.

Estos fármacos afectan principalmente canales VDCCs de tipo-L y, en mucho menor grado, tienen efecto a nivel del sistema nervioso central.

En cuanto al mecanismo de acción, estos fármacos se unen directamente a determinados segmentos transmembrana de la subunidad a 1 del canal. El grupo de las DHPs se une al segmento S6 de los dominios II y IV; los benzotiazepínicos (diltiazem) se unen al dominio III, IV entre el S5-S6, y los feni- lalquilamínicos se unen al dominio IV S6 (65).

Los bloqueadores de canales de $\mathrm{Ca}^{2+}$ se unen más rápidamente a células que presentan potenciales de membrana más despolarizados, lo que explica su mayor afinidad por las células musculares vasculares y por las células nodales que tienen potenciales de membrana alrededor de $-60 \mathrm{mV}$ comparadas con las células musculares auriculares, ventriculares y las fibras de Purkinje en las 
que su potencial es de $-90 \mathrm{mV}$ (15). Estos fármacos reducen la frecuencia de apertura de los canales de calcio en respuesta a la despolarización, teniendo como resultado una notable disminución en la corriente de calcio en el músculo liso y en el músculo cardiaco (54), generando una disminución en la contractilidad (Tabla 4) (66).

Tabla 4. Efectos cardiovasculares de fármacos usados en el sistema cardiovascular.

\begin{tabular}{|c|c|c|c|c|}
\hline Fármaco & $\begin{array}{c}\text { Vasodilatación } \\
\text { (flujo coronario) }\end{array}$ & $\begin{array}{c}\text { Supresión de la } \\
\text { contractilidad cardiaca }\end{array}$ & $\begin{array}{c}\text { Supresión de la } \\
\text { automaticidad } \\
\text { (Nodo SA) }\end{array}$ & $\begin{array}{c}\text { Supresión de la } \\
\text { conducción (Nodo AV) }\end{array}$ \\
\hline Amlodipina & NC & NC & NC & NC \\
\hline Diltiazem & 3 & NC & NC & NC \\
\hline Felodipina & NC & NC & 1 & NC \\
\hline Isradipina & 5 & 1 & 1 & 0 \\
\hline Nicardipina & 5 & 1 & 1 & 0 \\
\hline Nifedipina & 5 & NC & NC & NC \\
\hline Nimodipina & NC & 4 & 5 & 5 \\
\hline Nisoldipina & \multicolumn{2}{|c|}{4} & auriculoventricular. & \\
\hline Verapamil & Los efectos cardiovasculares elevados se clasifican desde efecto nulo (0) hasta más notorio (5), NC: no clasificado, SA: sinoauricular, AV: \\
\hline
\end{tabular}

Fuente: Elaborado por Lozano y Sánchez.

\section{Sistema cardiovascular}

En los vasos de resistencia periférica el calcio genera contracción en las células musculares lisas (ver Figura 6), los canales que permiten el ingreso de $\mathrm{Ca}^{2+}$ son las dianas específicas del verapamilo, diltiazem y nifedipino, precipitando la caída de $\mathrm{Ca}^{2+}$ citosólico generando en músculo cardiaco disminución de la conducción auriculoventricular y sinoauricular y en músculo liso vasodilatación. En las arritmias cardiacas los bloqueadores de canales de calcio disminuyen la frecuencia cardiaca y la velocidad de conducción a nivel nodal (63). En hipertensión los bloqueantes de los canales de
$\mathrm{Ca}^{2+}$ producen relajación arteriolar $\mathrm{y}$, por lo tanto, reducción en la resistencia vascular periférica. En angina de pecho disminuye la demanda de oxígeno reduciendo el trabajo cardiaco y permiten atenuar el vasoespasmo, mejorando el aporte de oxígeno al miocardio al aumentar el flujo sanguíneo coronario $(54,66)$.

\section{Sistema nervioso central}

La entrada de calcio en la terminación presináptica facilita la liberación de neurotransmisores y da lugar a la despolarización y propagación de la descarga (ver Figura 7). En la epilepsia, se busca impedir la propa- 
gación de la descarga a estructuras vecinas siendo los canales tipo $\mathrm{T}$ implicados en la propagación del impulso nervioso. Por otro lado, los bloqueadores de canales de $\mathrm{Ca}^{2+}$ actúan a nivel de las arterias cerebrales permitiendo la atenuación del vasoespasmos $(54,66)$.

\section{Efectos sistémicos de los bloqueadores de canales de $\mathrm{Ca}^{2+}$}

En el músculo liso se presenta una relajación. Al parecer el músculo liso vascular es el más sensible, pero puede verse relajación en el músculo liso bronquial, gastrointestinal y uterino. En el músculo esquelético no se deprimen las concentraciones de $\mathrm{Ca}^{2+}$ intracelular debido al gran tamańo del retículo endoplásmico. En vasoespasmo cerebral la nimodipina posee una gran afinidad por los vasos sanguíneos cerebrales, permitiendo la atenuación de este efecto.

\section{Proyecciones}

Recientes descubrimientos sobre las bases moleculares de la inactivación de los canales de $\mathrm{Ca}^{2+}$ en el proceso de excitación-contracción en células cardiacas y vasculares ha permitido dilucidar detalles estructurales de los canales de $\mathrm{Ca}^{2+}$, como la interacción de proteínas necesarias para la activación y finalización de las corrientes de $\mathrm{Ca}^{2+}(67)$, lo cual puede ayudar al desarrollo de nuevos agentes terapéuticos basados en los nuevos principios estructurales.
La terapéutica actual se ha direccionado al bloqueo de los canales de $\mathrm{Ca}^{2+}$ ubicados en la membrana plasmática. Sin embargo, los canales ubicados en el retículo endoplasmático (IP3 y RYR), son un potencial blanco terapéutico para el control de la función celular. Xantinas, adenosinas y algunos policationes, se han encontrado que son específicos para el receptor RyR. Esta información ayudará al desarrollo de agentes permeables de membrana de bajo peso molecular que presenten selectividad y, por lo tanto, pueden servir como agentes terapéuticos para controlar la liberación de $\mathrm{Ca}^{2+}$ intracelular desde el retículo endoplasmático (68).

Otro aspecto interesante es el papel de $\mathrm{Ca}^{2+}$ en tejido adiposo. El incremento de calcio intracelular parece que ejerce un papel regulador bifásico en la diferenciación del adipocito: en estadios tempranos, bloquea la diferenciación, y en estadios tardíos la estimula $(25,69,70)$. Recientemente se ha descrito que los canales TRPV1 estarían implicados en inhibición de la adipogénesis de preadipocitos 3T3-L1 (71).

Muchas investigaciones actuales están encaminadas a comprender los mecanismos moleculares implicados en la regulación de la actividad de estos canales y su relación con las vías de señalización (72-73). El conocimiento de estos mecanismos creará nuevos potenciales puntos de acción farmacológica. 


\section{Referencias}

1. Eisenman G, Dani JA. An introduction to molecular architecture and permeability of ion channels. Annual review of biophysics and biophysical chemistry. 1987;16:205-26.

2. Reuter H, Scholz H. A study of the ion selectivity and the kinetic properties of the calcium dependent slow inward current in mammalian cardiac muscle. The Journal of physiology. 1977;264(1):17-47.

3. Tang L, Gamal El-Din TM, Lenaeus MJ, Zheng N, Catterall WA. Structural Basis for Diltiazem Block of a Voltage-Gated $\mathrm{Ca}(2+)$ Channel. Molecular pharmacology. 2019;96(4):485-92.

4. Yue L, Navarro B, Ren D, Ramos A, Clapham DE. The cation selectivity filter of the bacterial sodium channel, $\mathrm{NaChBac}$. The Journal of general physiology. 2002;120(6):845-53.

5. Wang Y, Finol-Urdaneta RK, Ngo VA, French RJ, Noskov SY. Bases of Bacterial Sodium Channel Selectivity Among Organic Cations. Scientific reports. 2019;9(1):15260.

6. Barnes S, Bui Q. Modulation of calcium-activated chloride current via $\mathrm{pH}$-induced changes of calcium channel properties in cone photoreceptors. The Journal of neuroscience : the official journal of the Society for Neuroscience. 1991;11(12):401523.

7. Story GM, Peier AM, Reeve AJ, Eid SR, Mosbacher J, Hricik TR, et al. ANKTM1, a TRP-like channel expressed in nociceptive neurons, is activated by cold temperatures. Cell. 2003;112(6):819-29.

8. Yamakage M, Namiki A. Calcium channels--basic aspects of their structure, function and gene encoding; anesthetic action on the channels--a review. Canadian journal of anaesthesia $=$ Journal canadien d'anesthesie. 2002;49(2):151-64.

9. Miljanich GP, Ramachandran J. Antagonists of neuronal calcium channels: structure, function, and therapeutic implications. Annual review of pharmacology and toxicology. 1995;35:707-34.
10. Ghatta S, Nimmagadda D, Xu X, O'Rourke ST. Large-conductance, calcium-activated potassium channels: structural and functional implications. Pharmacology \& therapeutics. 2006;110(1):10316.

11. McCleskey EW, Fox AP, Feldman D, Tsien RW. Different types of calcium channels. The Journal of experimental biology. 1986;124:177-90.

12. McFadzean I, Gibson A. The developing relationship between receptor-operated and store-operated calcium channels in smooth muscle. British journal of pharmacology. 2002;135(1):1-13.

13. Villereal ML, Palfrey HC. Intracellular calcium and cell function. Annual review of nutrition. 1989;9:347-76.

14. Miller RJ. Multiple calcium channels and neuronal function. Science. 1987;235(4784):46-52.

15. Florez J, Armijo JA, Mediavilla A. Farmacología humana: Elsevier Masson; 201316 diciembre 2013. 1216 p.

16. Laube B, Kuhse J, Betz H. Evidence for a tetrameric structure of recombinant NMDA receptors. The Journal of neuroscience : the official journal of the Society for Neuroscience. 1998;18(8):2954-61.

17. Yi F, Traynelis SF, Hansen KB. Selective Cell-Surface Expression of Triheteromeric NMDA Receptors. Methods in molecular biology. 2017;1677:145-62.

18. Lieberman DN, Mody I. Regulation of NMDA channel function by endogenous $\mathrm{Ca}(2+)$-dependent phosphatase. Nature. 1994;369(6477):235-9.

19. Ehlers MD, Zhang S, Bernhadt JP, Huganir RL. Inactivation of NMDA receptors by direct interaction of calmodulin with the NR1 subunit. Cell. 1996;84(5):745-55.

20. Rycroft BK, Gibb AJ. Inhibitory interactions of calcineurin (phosphatase 2B) and calmodulin on rat hippocampal NMDA receptors. Neuropharmacology. 2004;47(4):505-14.

21. Cooper E, Couturier S, Ballivet M. Pentameric 
structure and subunit stoichiometry of a neuronal nicotinic acetylcholine receptor. Nature. 1991;350(6315):235-8.

22. Mazzaferro S, Bermudez I, Sine SM. Potentiation of a neuronal nicotinic receptor via pseudo-agonist site. Cellular and molecular life sciences : CMLS. 2019;76(6):1151-67.

23. Cheng H, Lederer WJ. Calcium sparks. Physiological reviews. 2008;88(4):1491-545.

24. Berridge MJ. Elementary and global aspects of calcium signalling. The Journal of experimental biology. 1997;200(Pt 2):315-9.

25. Lodish H. Biología celular y molecular. 5 ed. Panamericana EM, editor. Bogotá Ed. Médica Panamericana; 20052005.

26. Clapham DE, Julius D, Montell C, Schultz G. International Union of Pharmacology. XLIX. Nomenclature and structure-function relationships of transient receptor potential channels. Pharmacological reviews. 2005;57(4):427-50.

27. Clapham DE. TRP channels as cellular sensors. Nature. 2003;426(6966):517-24.

28. Vandewauw I, De Clercq K, Mulier M, Held K, Pinto S, Van Ranst N, et al. A TRP channel trio mediates acute noxious heat sensing. Nature. 2018;555(7698):662-6.

29. Schwarz EC, Wissenbach U, Niemeyer BA, Strauss B, Philipp SE, Flockerzi V, et al. TRPV6 potentiates calcium-dependent cell proliferation. Cell calcium. 2006;39(2):163-73.

30. Cai S, Fatherazi S, Presland RB, Belton CM, Roberts FA, Goodwin PC, et al. Evidence that TRPC1 contributes to calcium-induced differentiation of human keratinocytes. Pflugers Archiv : European journal of physiology. 2006;452(1):43-52.

31. Cai S, Fatherazi S, Presland RB, Belton CM, Izutsu KT. TRPC channel expression during calcium-induced differentiation of human gingival keratinocytes. Journal of dermatological science. 2005;40(1):21-8.
32. Boyce ST, Ham RG. Calcium-regulated differentiation of normal human epidermal keratinocytes in chemically defined clonal culture and serum-free serial culture. The Journal of investigative dermatology. 1983;81(1 Suppl):33s-40s.

33. Bertolino M, Llinas RR. The central role of voltage-activated and receptor-operated calcium channels in neuronal cells. Annual review of pharmacology and toxicology. 1992;32:399-421.

34. Jan LY, Jan YN. Voltage-sensitive ion channels. Cell. 1989;56(1):13-25.

35. Walker D, Bichet D, Campbell KP, De Waard M. A beta 4 isoform-specific interaction site in the carboxyl-terminal region of the voltage-dependent $\mathrm{Ca} 2+$ channel alpha 1A subunit. The Journal of biological chemistry. 1998;273(4):2361-7.

36. Hering S. beta-Subunits: fine tuning of $\mathrm{Ca}(2+)$ channel block. Trends in pharmacological sciences. 2002;23(11):509-13.

37. Singer D, Biel M, Lotan I, Flockerzi V, Hofmann F, Dascal N. The roles of the subunits in the function of the calcium channel. Science. 1991;253(5027):1553-7.

38. Wang M, Offord J, Oxender DL, Su TZ. Structural requirement of the calcium-channel subunit alpha2 delta for gabapentin binding. The Biochemical journal. 1999;342 ( Pt 2):313-20.

39. Gee NS, Brown JP, Dissanayake VU, Offord J, Thurlow R, Woodruff GN. The novel anticonvulsant drug, gabapentin (Neurontin), binds to the alpha2delta subunit of a calcium channel. The Journal of biological chemistry. 1996;271(10):5768-76.

40. Llinas R, Yarom Y. Oscillatory properties of guinea-pig inferior olivary neurones and their pharmacological modulation: an in vitro study. The Journal of physiology. 1986;376:163-82.

41. Ertel EA, Campbell KP, Harpold MM, Hofmann F, Mori Y, Perez-Reyes E, et al. Nomenclature of voltage-gated calcium channels. Neuron. 2000;25(3):533-5. 
42. Kamp TJ, Hell JW. Regulation of cardiac L-type calcium channels by protein kinase $\mathrm{A}$ and protein kinase C. Circulation research. 2000;87(12):1095102.

43. Clapham DE. Calcium signaling. Cell. 2007;131(6):1047-58.

44. Burdakov D, Petersen OH, Verkhratsky A. Intraluminal calcium as a primary regulator of endoplasmic reticulum function. Cell calcium. 2005;38(34):303-10.

45. Carafoli E. Calcium signaling: a tale for all seasons. Proceedings of the National Academy of Sciences of the United States of America. 2002;99(3):111522.

46. Brown EM, Vassilev PM, Hebert SC. Calcium ions as extracellular messengers. Cell. 1995;83(5):67982.

47. Hofer AM, Gerbino A, Caroppo R, Curci S. The extracellular calcium-sensing receptor and cell-cell signaling in epithelia. Cell calcium. 2004;35(3):297-306.

48. Chen YF, Chen YT, Chiu WT, Shen MR. Remodeling of calcium signaling in tumor progression. Journal of biomedical science. 2013;20:23.

49. Onal B, Gratz D, Hund TJ. Ca(2+)/calmodulin-dependent kinase II-dependent regulation of atrial myocyte late $\mathrm{Na}(+)$ current, $\mathrm{Ca}(2+)$ cycling, and excitability: a mathematical modeling study. American journal of physiology Heart and circulatory physiology. 2017;313(6):H1227-H39.

50. Burstenbinder K, Moller B, Plotner R, Stamm G, Hause G, Mitra D, et al. The IQD Family of Calmodulin-Binding Proteins Links Calcium Signaling to Microtubules, Membrane Subdomains, and the Nucleus. Plant physiology. 2017;173(3):1692708 .

51. Melzer W, Herrmann-Frank A, Luttgau HC. The role of $\mathrm{Ca} 2+$ ions in excitation-contraction coupling of skeletal muscle fibres. Biochimica et biophysica acta. 1995;1241(1):59-116.
52. Gehlert S, Bloch W, Suhr F. Ca2+-dependent regulations and signaling in skeletal muscle: from electro-mechanical coupling to adaptation. International journal of molecular sciences. 2015;16(1):1066-95.

53. Dayal A, Ng SFJ, Grabner M. Ca(2+)-activated $\mathrm{Cl}(-)$ channel TMEM16A/ANO1 identified in zebrafish skeletal muscle is crucial for action potential acceleration. Nature communications. 2019;10(1):115.

54. Hardman JG, Limbird LE, Gilman AG. Goodman \& Gilman. Las bases farmacológicas de la terapéutica. 13 ed. Interamericana M-H, editor. México: McGraw-Hill Interamericana; 20182018.

55. Sollner T, Whiteheart SW, Brunner M, Erdjument-Bromage $\mathrm{H}$, Geromanos $\mathrm{S}$, Tempst $\mathrm{P}$, et al. SNAP receptors implicated in vesicle targeting and fusion. Nature. 1993;362(6418):318-24.

56. Tolar LA, Pallanck L. NSF function in neurotransmitter release involves rearrangement of the SNARE complex downstream of synaptic vesicle docking. The Journal of neuroscience : the official journal of the Society for Neuroscience. 1998;18(24):10250-6.

57. Golby JA, Tolar LA, Pallanck L. Partitioning of $\mathrm{N}$-ethylmaleimide-sensitive fusion (NSF) protein function in Drosophila melanogaster: dNSF1 is required in the nervous system, and dNSF2 is required in mesoderm. Genetics. 2001;158(1):265-78.

58. Whitehead JP, Molero JC, Clark S, Martin S, Meneilly G, James DE. The role of $\mathrm{Ca} 2+$ in insulin-stimulated glucose transport in 3T3L1 cells. The Journal of biological chemistry. 2001;276(30):27816-24.

59. Grespan E, Giorgino T, Arslanian S, Natali A, Ferrannini E, Mari A. Defective Amplifying Pathway of beta-Cell Secretory Response to Glucose in Type 2 Diabetes: Integrated Modeling of In Vitro and In Vivo Evidence. Diabetes. 2018;67(3):496-506.

60. Henquin JC. Triggering and amplifying pathways 
of regulation of insulin secretion by glucose. Diabetes. 2000;49(11):1751-60.

61. Berridge MJ. Calcium signalling and cell proliferation. BioEssays : news and reviews in molecular, cellular and developmental biology. 1995;17(6):491500 .

62. Berridge MJ. Inositol trisphosphate and calcium signalling mechanisms. Biochimica et biophysica acta. 2009;1793(6):933-40.

63. Garcia-Cozar FJ, Okamura H, Aramburu JF, Shaw KT, Pelletier L, Showalter R, et al. Two-site interaction of nuclear factor of activated $T$ cells with activated calcineurin. The Journal of biological chemistry. 1998;273(37):23877-83.

64. Hardingham GE, Chawla S, Johnson CM, Bading H. Distinct functions of nuclear and cytoplasmic calcium in the control of gene expression. Nature. 1997;385(6613):260-5.

65. Fons N. Textbook of Drug Design and Discovery, Fifth Edition. Yale J Biol Med. 2017;90(1):160-.

66. Katzung BG. Farmacología básica y clínica. 14 ed. Serrano H, editor. México: McGRAW-HILL/ INTERAMERICANA EDITORES, S.A. de C.V.; 20192019.

67. Abernethy DR, Soldatov NM. Structure-functional diversity of human L-type Ca2+ channel: perspectives for new pharmacological targets. The Journal of pharmacology and experimental therapeutics. 2002;300(3):724-8.

68. Xu L, Tripathy A, Pasek DA, Meissner G. Ruthenium red modifies the cardiac and skeletal muscle $\mathrm{Ca}(2+)$ release channels (ryanodine receptors) by multiple mechanisms. The Journal of biological chemistry. 1999;274(46):32680-91.

69. Shi H, Halvorsen YD, Ellis PN, Wilkison WO, Zemel MB. Role of intracellular calcium in human adipocyte differentiation. Physiological genomics. 2000;3(2):75-82.

70. Goudarzi F, Mohammadalipour A, Khodadadi I, Karimi S, Mostoli R, Bahabadi M, et al. The Role of Calcium in Differentiation of Human Adipose-Derived Stem Cells to Adipocytes. Molecular biotechnology. 2018;60(4):279-89.

71. Zhang LL, Yan Liu D, Ma LQ, Luo ZD, Cao TB, Zhong J, et al. Activation of transient receptor potential vanilloid type-1 channel prevents adipogenesis and obesity. Circulation research. 2007;100(7):1063-70.

72. Asad, A., Florencia Zuccato, C., Nicola Candia, A., Florencia Gottardo, M., Moreno Ayala, M., Theas, M., Seilicovich, A., \& Candolfi, M. (2019). Papel del péptido mitocondrial humanina como blanco terapéutico en cáncer y neurodegeneración. NOVA, 17(32), 9-24 Disponible en: https://revistas.unicolmayor.edu.co/index.php/nova/article/ view/1029.

73. Koch WJ, Ellinor PT, Schwartz A. cDNA cloning of a dihydropyridine-sensitive calcium channel from rat aorta. Evidence for the existence of alternatively spliced forms. The Journal of biological chemistry. 1990;265(29):17786-91. 